\title{
Rare Earths (La, Y, and Nd) Adsorption Behaviour towards Mineral Clays and Organoclays: Monoionic and Trionic Solutions
}

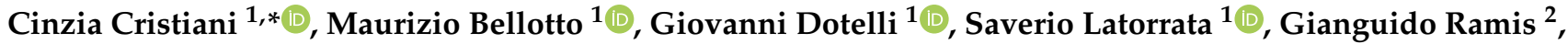 \\ Paola Gallo Stampino ${ }^{1}$, Elena Maria Iannicelli Zubiani ${ }^{1}$ and Elisabetta Finocchio ${ }^{2, *}$
}

1 Dipartimento di Chimica, Materiali e Ingegneria Chimica "Giulio Natta", Politecnico di Milano, Piazza Leonardo Da Vinci 32, 20133 Milano, Italy; maurizio.bellotto@opigeo.eu (M.B.); giovanni.dotelli@polimi.it (G.D.); saverio.latorrata@polimi.it (S.L.); paola.gallo@polimi.it (P.G.S.); elenamaria.iannicelli@polimi.it (E.M.I.Z.)

2 Dipartimento di Ingegneria Civile, Chimica ed Ambientale, Università di Genova, Via all'Opera Pia 15, 16145 Genova, Italy; gianguido.ramis@unige.it

* Correspondence: cinzia.cristiani@polimi.it (C.C.); elisabetta.finocchio@unige.it (E.F.)

Citation: Cristiani, C.; Bellotto, M.; Dotelli, G.; Latorrata, S.; Ramis, G.; Gallo Stampino, P.; Zubiani, E.M.I.; Finocchio, E. Rare Earths (La, Y, and $\mathrm{Nd}$ ) Adsorption Behaviour towards Mineral Clays and Organoclays: Monoionic and Trionic Solutions. Minerals 2021, 11, 30. https://doi.org/ $10.3390 / \min 11010030$

Received: 6 November 2020 Accepted: 25 December 2020 Published: 29 December 2020

Publisher's Note: MDPI stays neutral with regard to jurisdictional claims in published maps and institutional affiliations.

Copyright: () 2020 by the authors. Licensee MDPI, Basel, Switzerland. This article is an open access article distributed under the terms and conditions of the Creative Commons Attribution (CC BY) license (https: / creativecommons.org/ licenses/by/4.0/).

\begin{abstract}
Metals from electric and electronic waste equipment (WEEE) can be recovered by dissolution with acids followed by liquid-liquid extraction. A possible alternative to liquid-liquid extraction is liquid-solid adsorption, where sorbents efficiency is the key factor for process efficiency. In this respect, aim of this paper is the study of the behaviour of two solid sorbents for the recovery of Rare Earths (REs) —in particular, La, Nd, and Y-from scraps of end-of-Life (EOL) electronic equipment. Two solid matrices were considered: a pristine montmorillonite clay and a modified-montmorillonite clay intercalated with a commercial pentaethylen-hexamine. The capture ability of the solids was tested towards single-ion $\mathrm{La}, \mathrm{Nd}$, and $\mathrm{Y}$ solutions and a multi-element solution containing the three ions. Before and after the uptake step, samples of both the solid and liquid phases were analysed. For both sorbents, at lower metal initial concentrations, the ions were captured in similar amount. At higher concentrations, pure clay showed a high total uptake towards La ions, likely due to surface interactions with clay sites. The organoclay preferentially interacts with $\mathrm{Nd}$ and $\mathrm{Y}$. Considering the presence of the polyamine, this behaviour was related to ion coordination with the amino groups. The capture behaviour of the two sorbents was related to the different physicochemical properties of the ions, as well as to the ionic radius.
\end{abstract}

Keywords: trionic solutions; organoclay; lanthanum; yttrium; neodymium ions; capture mechanism

\section{Introduction}

In the modern technologies, Rare Earths (REs) are key components, especially applied in electronic devices. It is expected that, in the near future, an increasing demand of REs will occur [1]. Due to their wide application, one of the critical points in their use is supply. Indeed, RE mines are restricted to only a few geographical districts, with the largest mining fields in Asia-mainly, China [2]. Therefore, even if world production can satisfy the global demand, monopoly, difficult production technologies, and environmental risks make RE supply a serious problem [3]. The mitigation of this problem could derive from the use of secondary REs coming from wise waste management and recycling. Indeed, REs are contained in various electrical and electronic wastes-mainly electric and electronic devices but, also, in other industrial waste residues (e.g., catalysts) [4-8].

Every year, tons of small electrical and electronic equipment at the end of their lives are disposed of in landfills, wasting raw materials contained therein and potentially recoverable, even if they are rich in precious and strategic metals [9-11]. Electric and electronic wastes (WEEE) management has been documented as the fastest-growing waste stream in the world, with a growth rate of 3-5\% per year [12]. Electronic waste is, in fact, 
generated two to three times faster than others, both due to the rapid increase in consumer electronic devices and their diffusion [10].

The approach known as "urban mining", which is based on the development of "good practices" for the collection, transport, recycling, and recovery of precious materials contained in these products at the end of their lives, would lead to undeniable socioeconomic and environmental benefits in line with the pillars of sustainability and sustainable development $[13,14]$.

For these reasons, the study of an efficient method of REs and precious metals recovery from WEEE is of clear interest. Moreover, RE recovery from aqueous solutions is a crucial point also in view of environmental and human health protection.

One of the problems in RE recovery is their close similarity in view of their electronic configuration, which results in a difficult and expensive separation and recovery. In addition to that, low environmental impact technologies would be welcome, to replace some of those conventionally applied.

Presently, one of the processes to recover metals from WEEE is their dissolution with acids, followed by liquid-liquid extraction. Although industrially applied, these processes could present environmental issues due to impacts connected to the use of chemicals [15-17].

Among others, adsorption (solid/liquid) is able to remove metal ions from aqueous solutions with high efficiency, low costs, and with a "sustainable approach" when natural sorbents are applied. The efficiency of the process is the key factor, and it depends on the adsorbent materials; therefore, the study and development of solids with improved capability to capture and release metals in a solution is of fundamental importance for the implementation of the process on an industrial scale.

The results of extensive laboratory testing on model solutions indicate that this approach may be an interesting and viable option. In recent years, various natural, synthesized, and functionalized sorbents were investigated for an efficient adsorption of RE ions [18-27].

The adsorption capability of natural clay-mainly smectite or montmorillonite [28-31] are well-known, and also, the use of chelating agents has been reported. Chelating molecules, indeed able to strongly coordinate metal ions, are widely applied in the industry, as well as in consumer products [19].

In this respect, the aim of this paper is to demonstrate the feasibility of the use of pristine and modified clays for the recovery of Rare Earths (REs) from aqueous solutionsnamely, $\mathrm{La}, \mathrm{Nd}$, and $\mathrm{Y}$. For this purpose, an experimental campaign was designed. Two solid matrices were considered: (a) pristine montmorillonite clay and (b) modified-montmorillonite clay intercalated with a commercial pentaethylen-hexamine used as chelating agent. The capture ability of both solids was tested towards six solutions of different concentrations for each ion.

The capture and the release results were interpreted at the light of the interaction of the single ions with the solid sorbent, as well as on the bases of the physicochemical properties of the metal ions (such as, e.g., ionic radius, electronic configurations, electronegativity, and hydrolysis constant). Additionally, the preliminary results on the ion uptakes in mixed solutions of different concentrations, i.e., containing the three ions together, were reported. The evaluation of possible competitions among the ions or selective capture by the two solids were also assessed. Moreover, also, the sorbents before and after the uptakes were analysed.

The final target was the comprehension of the phenomena occurring during the process to better apply and manage the proposed sorbents and capture process in real practice.

\section{Materials and Methods}

Natural Ca-montmorillonites, (STx-1b Clay Minerals Society; STx in the text), pristine and intercalated with a linear penta-ethylene-hexamine (Sigma Aldrich; STx-L6 in the text), were used as sorbent solids. 
Pristine clay composition, as reported in the Supplier data sheet, was ${ }^{\mathrm{IV}} \mathrm{Si}_{4.0}{ }^{\mathrm{VI}}\left(\mathrm{Al}_{1.21} \mathrm{Fe}^{3+}\right.$ $\left.{ }_{0.05} \mathrm{Mg}^{2+}{ }_{0.36} \mathrm{Ti}_{0.02}\right)^{\mathrm{XII}}\left(\mathrm{Ca}_{0.14} \mathrm{Na}_{0.02} \mathrm{~K}_{0.01}\right) \mathrm{O}_{10}(\mathrm{OH})_{2}$. Moreover, the following morphological properties were measured for the powder: particle size $=20 \pm 10 \mu \mathrm{m}$, surface area $=86.5 \mathrm{~m}^{2} / \mathrm{g}$, pore volume $=0.35 \mathrm{~cm}^{3} / \mathrm{g}$, and a bimodal distribution of pores dimensions $=77$ and $140 \AA$.

The preparation of the organoclays was performed according to a procedure developed elsewhere, which implied the mixing of the clay with the aqueous polyamine solution in a jacketed reactor under vigorous stirring ( $500 \mathrm{rpm}$ ) for $90 \mathrm{~min}$ at a controlled temperature of $30^{\circ} \mathrm{C}$, at $\mathrm{pH}=11$ (i.e., the $\mathrm{pH}$ of the polyamine solution). This procedure allowed for the intercalation of $0.40 \mathrm{mmol} / \mathrm{g}_{\text {clay }}$ of polyamine without ion exchange [32].

The cation exchange capacity (CEC) of the clay, determined according to [33], corresponded to $1.24 \mathrm{mmol}$ of the charges/g. This value is preserved in the case of the organoclay, because the intercalation of the polymer in its neutral form occurred without ion exchanges. The absence of ion exchanges was also confirmed by the absence of $\mathrm{Ca}$ ions in the solution upon polymer intercalation [32].

Monoionic and trionic solutions were prepared by dissolving $\mathrm{La}\left(\mathrm{NO}_{3}\right)_{3} \cdot 6 \mathrm{H}_{2} \mathrm{O}, \mathrm{Y}\left(\mathrm{NO}_{3}\right)_{3}$. $6 \mathrm{H}_{2} \mathrm{O}$, and $\mathrm{Nd}\left(\mathrm{NO}_{3}\right)_{3} \cdot 6 \mathrm{H}_{2} \mathrm{O}$, (all 99.9\% from Sigma Aldrich) in deionized water. Other chemicals were $\mathrm{HNO}_{3}$ (ACS, Sigma Aldrich) and $\mathrm{NaOH}$ (ACS, Sigma Aldrich).

Thirty-six monoionic and 6 trionic solutions were analysed in a wide range of concentrations, i.e., $10-100 \mathrm{mmol} / \mathrm{L}$. In the case of trionic solutions, the molar ratio among components $\mathrm{La} / \mathrm{Nd} / \mathrm{Y}=1 / 1 / 1$ was maintained for all the experiments (Table S1, Supporting Information).

Both uptake and release tests were performed according to a standard procedure previously developed [20] and sketched in Figure 1.

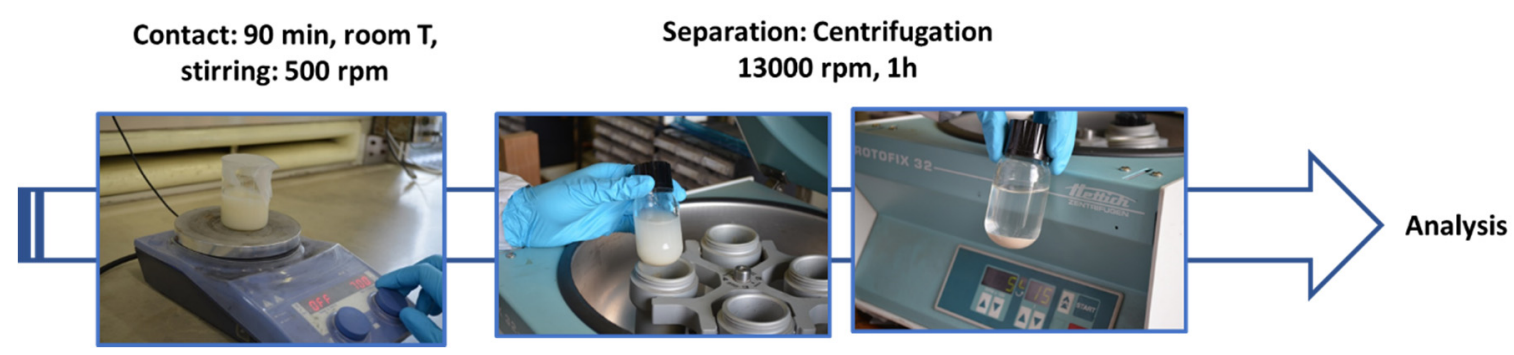

Figure 1. Procedure of the capture and release processes.

In capture experiments, $2 \mathrm{~g}$ of sorbent were contacted with $50 \mathrm{~mL}$ of solution under stirring at $500 \mathrm{rpm}$ at room temperature (Figure 1) for $90 \mathrm{~min}$. The reaction was performed at the $\mathrm{pH}$ values of the original solutions. Before uptake, the measured $\mathrm{pH}$ was in the range 5.5-6 for the La and $\mathrm{Y}$ monoionic solutions, and 3 for the $\mathrm{Nd}$ one. In the case of all the trionic solutions, the $\mathrm{pH}$ range was 5.0-5.3.

Upon contact with the sorbents, a pH of 5.5 was detected for all the solutions, which was kept constant the entire contact time. Therefore, during the experiments, the $\mathrm{pH}$ was measured (Mettler Toledo FE20/EL20 digital pH meter), but no $\mathrm{pH}$ correction was applied.

The absence of hydrolysis was checked by MEDUSA software calculation (version 16.1); the plots are reported in the Supplementary Information (Figures S1-S4). According to the literature [34,35], in these experimental conditions, no hydrolysis occurred.

Release tests were performed, putting in contact $1.3 \mathrm{~g}$ of the solid after uptake with $50 \mathrm{~mL}$ of a $\mathrm{HNO}_{3}$ solution $(\mathrm{pH}=1)$ under vigorous stirring $(500 \mathrm{rpm})$ at room temperature for 90 minutes.

After both uptake and release operations, the solid and liquid phases were separated by centrifugation at 13,000 rpm for $1 \mathrm{~h}$ (HETTICH 32 RotoFix centrifuge, Hettich, Westfalen, Germany).

Analyses were performed to measure the contents of $\mathrm{Y}, \mathrm{La}$, and $\mathrm{Nd}$, the ions of interest, as well as the $\mathrm{Ca}$ and $\mathrm{Mg}$ ions present in the clay matrix. All the metal ion concentrations in 
the solutions were measured by inductively coupled plasma-optical emission spectroscopy (ICP-OES) analyses using a Perkin Elmer Optima 2000DV spectrometer (Labx, Midland, $\mathrm{ON}$, Canada). The average of three measurements is reported, and the measurement error estimated from the replicate measurements is within $1 \%$. Captured REs were determined by the difference between the initial and residual ion contents before and after the capture process. Ion determination was performed considering interferences when present.

Sorbent solids were analysed by X-ray-diffraction analysis (BRUKER D8, Bruker, Billerica, MA, USA) in the range $3-30^{\circ}$, applying a $\mathrm{Cu}-\mathrm{K} \alpha$ radiation $1.5418 \AA$, a graphite monochromator, a step scan of $0.02^{\circ}$, and a counting time of 1 second per step. The X-ray diffraction (XRD) line profile analysis was performed with TOPAS P software (version 7, BrukerAXS, Karlsruhe, Germany), and the refined profiles were used for the determination of the reflection positions. The goniometer was daily calibrated with the Si NIST, National Institute of Standards and Technology standard SRM 640f, and the instrumental errors in the peak positions were limited to the sample displacement and sample transparency, contributing, at most, an uncertainty of $\pm 0.003 \mathrm{~nm}$.

\section{Results and Discussion}

\subsection{Monoionic Solutions}

\subsubsection{Uptake}

The capture behaviour in monoionic solutions by STx (a) and STx-L6 (b) determined by ICP-OES (estimated errors of $1 \%$ are within the symbol dimensions), as a function of the initial ion content, is plotted in Figure 2. The selected measuring unit for the ionic content, i.e., $\mathrm{mmol}_{\text {ion }} / \mathrm{g}_{\text {sorbent }}$, allows for a direct qualitative and quantitative comparison of the results.
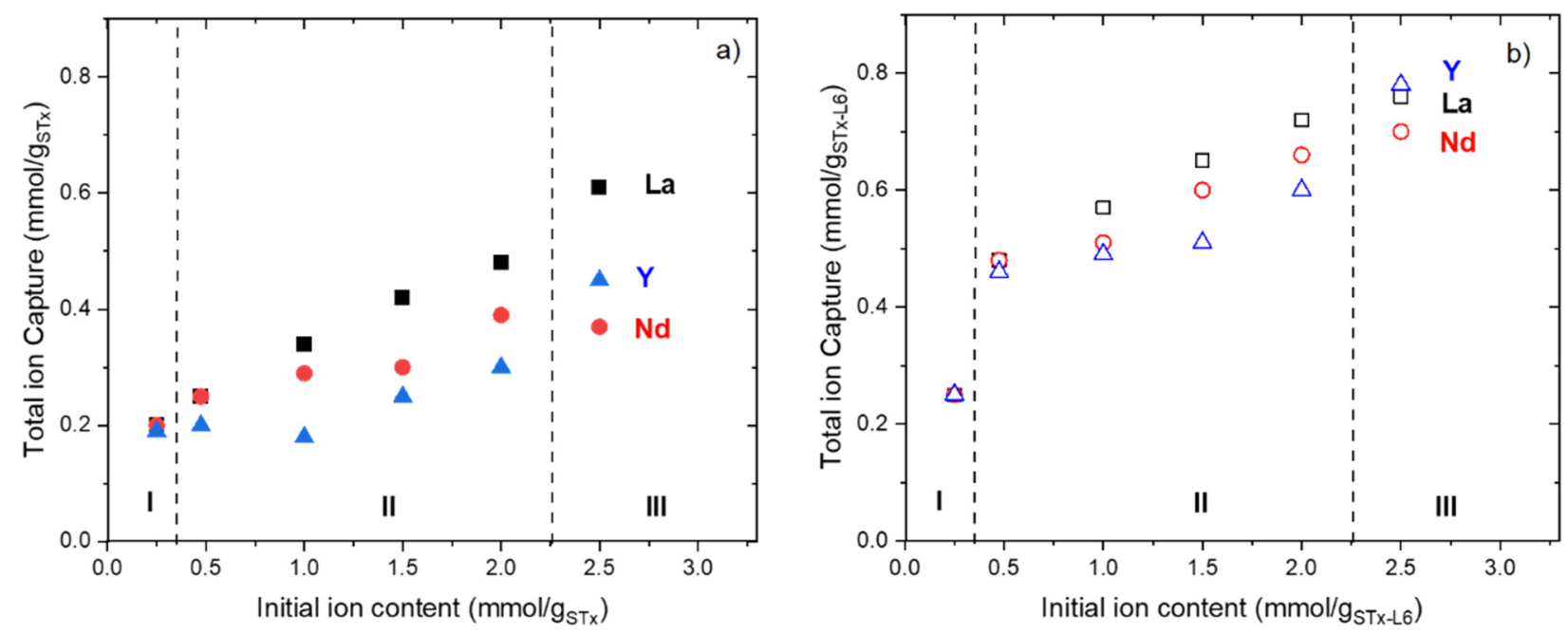

Figure 2. Total capture as a function of the initial ion contents for: (a) pristine STx and (b) modified STx-L6. (Regions I, II, and III are shown only as an eye guide).

In Figure 2, three different regions are considered; however, Region I, II, and III, have no scientific meaning but are only used as an eye guide to help the readers to follow more easily the description of the complex experimental data.

A very similar behaviour was found for the three ions in the presence of both sorbent solids. In detail:

Region I. Initial ion content lower than $0.5 \mathrm{mmol}_{\text {ion }} / \mathrm{g}_{\text {sorbent }}$. At the lowest concentrations, no difference was observed among the uptake of the three ions. $\mathrm{La}, \mathrm{Nd}$, and $\mathrm{Y}$ are captured at the same extent, at least, to reach the total ion uptake (Figure 2a,b). Moreover, a slightly higher uptake was always detected for STx-L6 (Figure 2b).

Region II. Initial ion content in the range $0.5-2.0 \mathrm{mmol}_{\text {ion }} / \mathrm{g}_{\text {sorbent }}$. In this range, a linear increase of the uptake is observed (Figure 2a,b). In the pristine clay, captured La is 
always a bit higher than $\mathrm{Nd}$ and $\mathrm{Y}$, while the differences are very low-at least negligiblewhen STx-L6 is used. Captures by the organoclay are always largely higher than those of STx, at least twice as much as those of the pristine solid.

Region III. Initial ions content higher than $2.0 \mathrm{mmol}_{\text {ion }} / \mathrm{g}_{\text {sorbent. }}$. In the last point of the curves, a difference in capture behaviour is manifest. While La ions are always better captured in unmodified STx, no differences are found when STx-L6 is applied; indeed, the organoclay is able to capture the three ions to the same extent.

The total capture by clay and organoclay can be explained by considering the typical interactions of the ion-sorbent solid. Capture can be the result of different mechanismsnamely, ion exchange, surface sorption, and, in the case of the organoclay, polyamine-ion coordination [24].

The activation of one or more of these mechanisms during capture depends mainly on the ion nature and clay or organoclay composition [21,24]. Indeed, clay interlayer cations; chemical composition; and structure of the organic modifier, ionic radii, and valence of the ions are some of the parameters that drive the capture mechanisms.

Therefore, the total ions uptake was further analysed by decomposing it in their three contributions. The ion exchange reaction was evaluated first; it can be active in both sorbent solids. Indeed, before uptake, Ca ions naturally present in pristine STx are still present in STx-L6, being the polyamine intercalated without exchange [32]. The extent of the ions exchange upon uptake was calculated on the basis of $\mathrm{Ca}$ ions released in the contacting solutions. This number accounts for $\mathrm{La}, \mathrm{Nd}$, or $\mathrm{Y}$ replacing $\mathrm{Ca}^{2+}$ in the interlayer to maintain the charge balance.

According to previous reports [24], to quantify the ion exchange, $\mathrm{Ca}^{2+}$ and $\mathrm{Mg}^{2+}$ ions present in the pristine organoclay as measured by the CEC (cations exchange capacity) and in solution after uptake as measured by ICP-OES were considered. In practice, only $\mathrm{Ca}^{2+}$ ions were considered, because a negligible amount of $\mathrm{Mg}^{2+}$ ions $\left(7.10^{-2} \mathrm{mmol} / \mathrm{g}\right)$ was released during the capture process. Therefore, $\mathrm{RE}^{3+}$ are intercalated via displacement of $\mathrm{Ca}^{2+}$ to maintain the electroneutrality. However, even at lower RE concentrations, captured ions exceeded the charge compensation, pointing out the presence of the other mechanisms.

Exchanged $\mathrm{REs}^{3+}$ were calculated according to Equation (1):

$$
C \mathrm{RE}_{\text {exchanged }}=\left(\mathrm{CC} a_{\text {out }} \cdot \text { charge } \mathrm{Ca}\right) / \text { charge } \mathrm{RE}
$$

The excess REs ions, resulting from the difference between the total (measured by ICP) and the exchanged ones, are thus involved in either the surface adsorption or coordination (by the amino groups) (Equation (2)):

$$
C \mathrm{RE}_{\text {surface adsorbed or coordinated }}=C \mathrm{RE} \text { tot }-C \mathrm{RE}_{\text {exchanged }}
$$

Both the $\mathrm{NH} / \mathrm{NH}_{2}$ groups of the amine and the structural $\mathrm{OHs}$ of the clay are supposed to be free for adsorption; however, adsorption by the hydroxyls was supposed to be negligible.

$\mathrm{Y}, \mathrm{Nd}$, and La, captured by both sorbents via the exchange mechanism as a function of the initial ion contents, are plotted in Figure 3a,b.

From a qualitative point of view, the sorbents showed very close behaviours, suggesting that polyamine has no influence on the exchange mechanism. The lower exchange capability of STx-L6 is related to the interlayer composition. The organoclay interlayer, being more crowded and sterically hindered due to the presence of the polyamine, is less prone to Ca replacement [21,24]. 

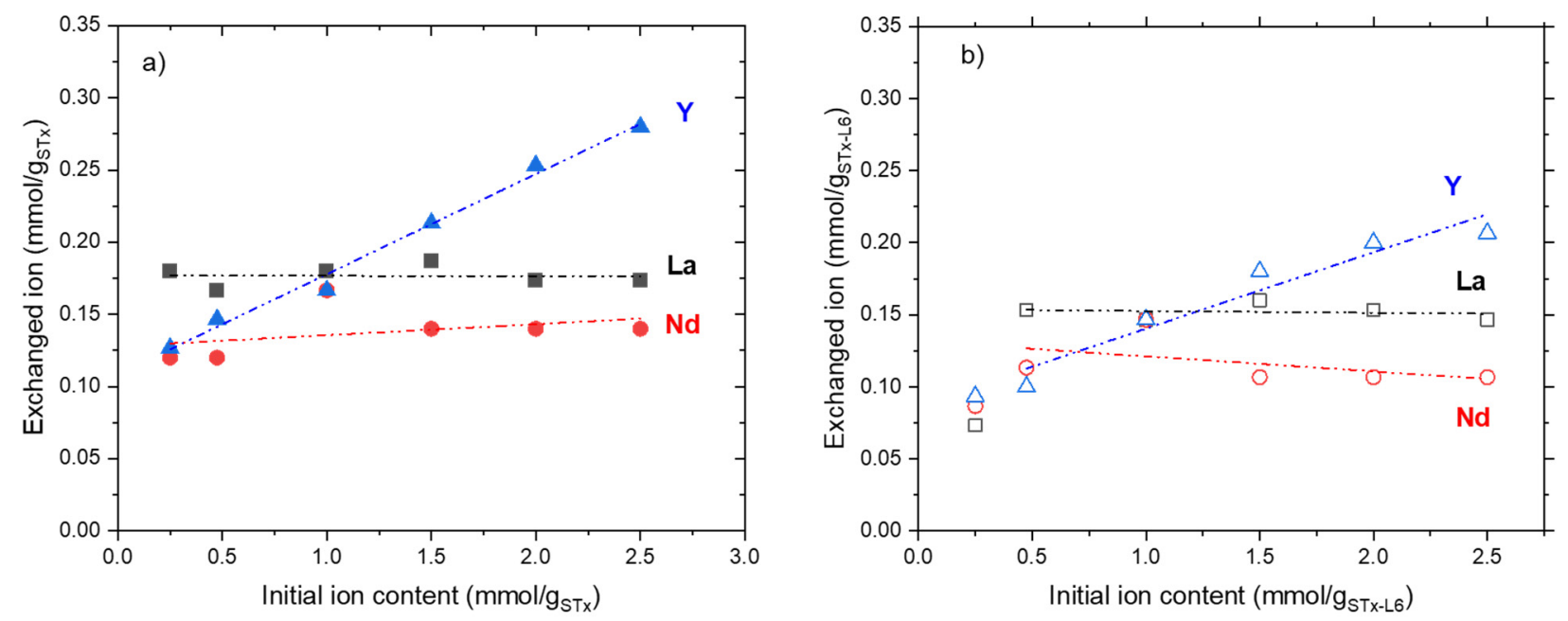

Figure 3. Exchanged ions as a function of the initial ion contents for: (a) pristine STx and (b) modified STx-L6.

In turn, marked differences were observed among the single ion behaviours (Figure 3a,b). At the lowest initial ions content, a larger amount of $\mathrm{La}\left(0.18 \mathrm{mmol} / \mathrm{g}_{\mathrm{Stx}}\right)$ than $\mathrm{Nd}$ and $\mathrm{Y}$ $\left(0.125 \mathrm{mmol} / \mathrm{g}_{\mathrm{Stx}}\right)$ were captured by pristine STx (Figure 3a). On the contrary, in the case of the organoclay, $\mathrm{Y}, \mathrm{La}$, and $\mathrm{Nd}$ were exchanged in a very limited extent $\left(0.075-0.085 \mathrm{mmol} / \mathrm{g}_{\mathrm{STx}-\mathrm{L} 6}\right)$, and the process appeared insensitive to the nature of the ions (Figure 3b). Possibly, at such a low ionic concentration, exchange processes are further limited by the presence of polyamine, and the selectivity cannot be detected due to the low amount of exchanged ions.

For both solids, when the initial ions content was increased, the exchange mechanism appeared to be highly favoured for $\mathrm{Y}$ ions. Instead, almost constant uptakes of $\mathrm{La}$ and $\mathrm{Nd}$ were measured in all the investigated ranges of concentration. Exchanged Nd was always lower than La.

Considering the slopes of the La and $\mathrm{Nd}$ lines, almost parallel, it can be concluded that these ions interact with the clay in a similar way.

However, the exchange never exceeded $0.25-0.30 \mathrm{mmol}_{\text {ion }} / \mathrm{g}_{\text {sorbent }}$, and, in any case, the exchange contribution never accounted for the total uptake, being, in most cases, onefourth to one-third of the total uptake. Therefore, additional contributions of the other mechanisms, i.e., surface adsorption and ions coordination, must be considered.

As already reported [20,21,24], the adsorbed amount of ions for STx and the adsorbed and coordinated amount for STx-L6 can be calculated according to Equation (2), by the difference between the total and exchanged uptakes. The results are reported in Figure $4 a, b$. Once more, the behaviour of the two sorbent solids was very close: La and $\mathrm{Nd}$ showed a linear trend, while $Y$ showed a constant adsorption. The sharp increase of $Y$ uptake at the highest concentration can be related to the surface adsorption of $Y$ ions in excess of what can be exchanged or coordinated. In the case of STx, only the adsorption contribution was present, while the higher capture, observed in STx-L6, was due to the additional coordination effect of polyamine. Regarding the capture by STx-L6, it was not possible to separate the contribution of the coordination and of the surface adsorption.

The coordination contribution is clearly present in STx-L6, i.e., a largely higher capture than STx was shown at any initial ion content (Figure $4 b$ ). This contribution accounts for the higher total uptake found for the STx-L6 sorbent (Figure 2b). In the presence of polyamine, the La and Nd uptakes are overlapped and largely higher than that of $\mathrm{Y}$.

The peculiar behaviour of $Y$ ions could be explained by considering that they are able to replace Ca ions to a large extent, and apparently, they are less available for adsorption or coordination. 

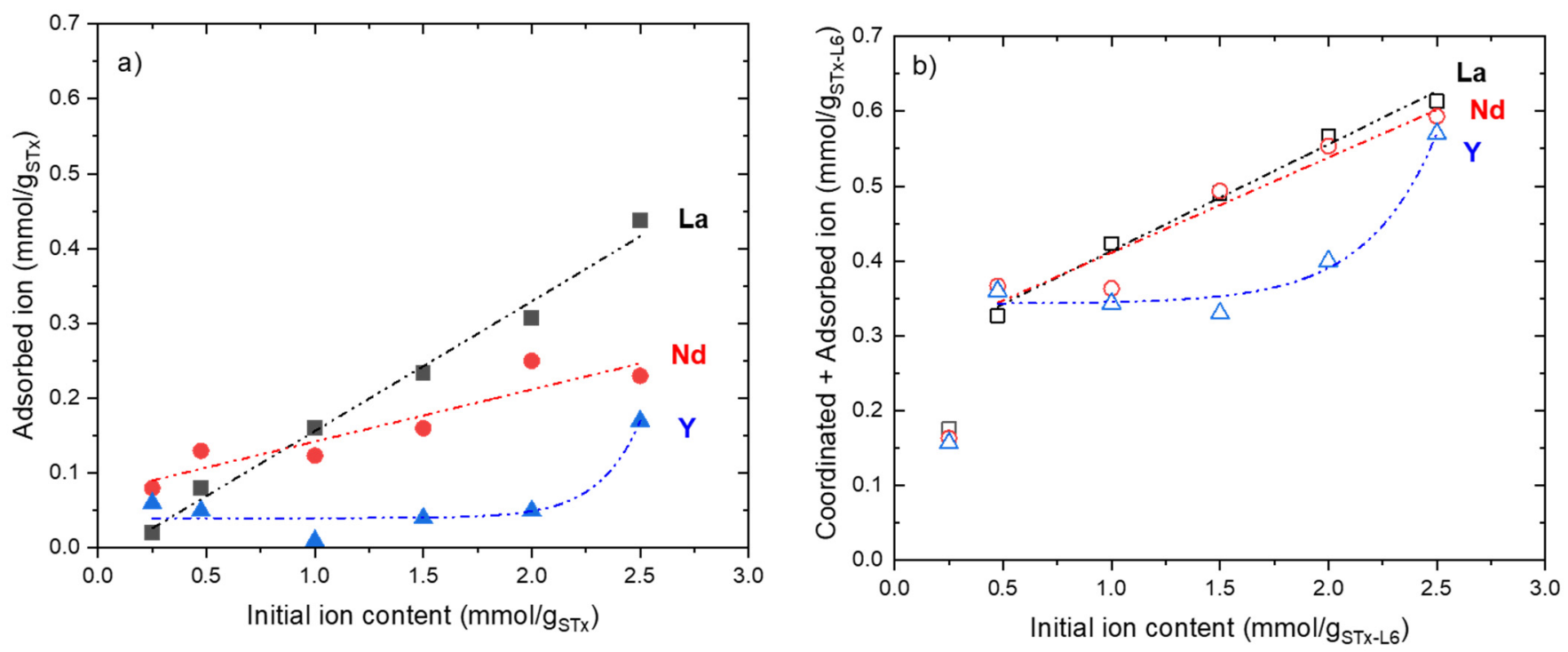

Figure 4. Adsorbed ions for pristine STx (a) and adsorbed plus coordinated ions for modified STx-L6 (b) as a function of the initial ion contents.

It has been reported in the literature that ion exchange can be followed by measuring clay interlayer expansion or contraction, depending on the extent of the $\mathrm{Ca}$ ion replacement. The interlayer dimension is, indeed, related to the dimension of cations or molecules occupying it $[20,32,36]$.

Accordingly, XRD was performed on the STx samples after the uptake process. The spectra collected for the lower and the higher initial concentration are reported in Figure 5.

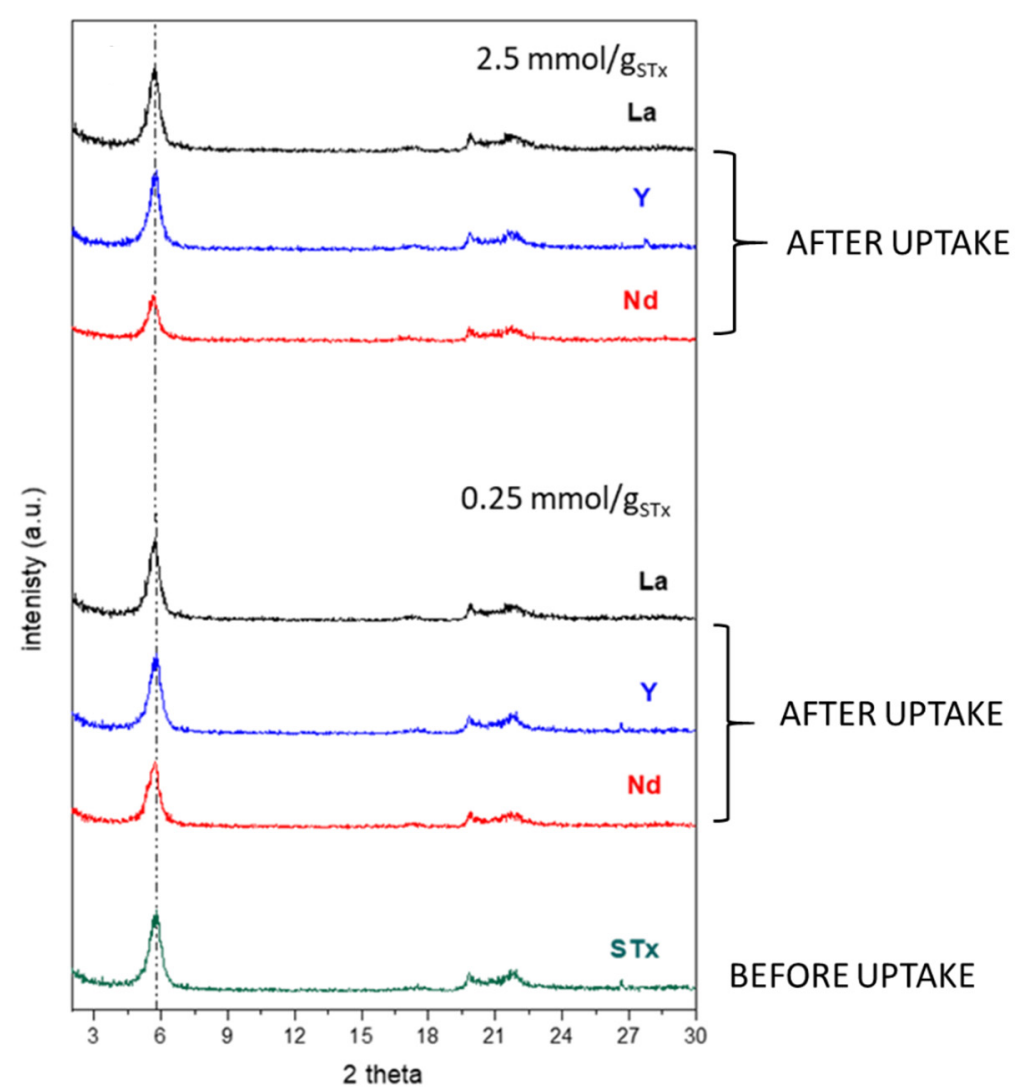

Figure 5. X-ray-diffraction (XRD) of pristine STx before and after the uptake reactions at two different initial ion contents. 
No shift of the basal reflection was apparent; thus, no modification of the interlayer distance was observed, suggesting that the close similarity among the ionic radii of $\mathrm{La}, \mathrm{Nd}$, $\mathrm{Y}$, and Ca possibly prevent an appreciable interlayer change. Therefore, XRD is unable to distinguish among the different interlayer cations. Regarding STx-L6, very limited shifts have been reported in the literature in the case of La capture from solutions of similar compositions as those reported here [24]. Combining different characterization techniques, it has been demonstrated that changes in $\mathrm{d}_{001}$ were related to the interlayer water molecule displacement upon intercalation of the La ions. Therefore, XRD analysis in this case was unable to differentiate the ions. Accordingly, further XRD analyses on the solids exchanged with $\mathrm{Y}$ and $\mathrm{Nd}$ were not performed.

For the application of the solids in real conditions, knowledge of the ions-sorbent interaction relationships is fundamental. Indeed, the application of the sorbent as a "black box" hardly will allow the implementation of the process here proposed at the industrial level. Scaling up, indeed, generally requires adaptation of the materials developed at the lab scale to an "in-field" situation. Therefore, a possible explanation of the observed behaviour on a scientific basis could be helpful to better manage and control the sorbent and the related process.

Accordingly, different physicochemical properties of the ions were considered to explain the observed different affinities of the metal ions towards the solid sorbents here proposed. According to the literature, several physicochemical properties of the metal itself, such as the ionic radius, charge density, hydrolysis constant, electronegativity, standard reduction potential, and so on, might influence the ion sorption process over natural and modified minerals [37], and in the following paragraphs, we will discuss the effect of selected parameters on the adsorption of La, Y, and Nd Rare Earths on the STx and STx L6 solid matrix.

From the data of the total uptakes reported in previous paragraphs (Figure 2), when the same adsorption conditions (temperature, $\mathrm{pH}$, and concentration) and initial concentrations were applied, both pristine and modified clays showed an increased adsorption of all the REs on increasing the initial ionic concentration. A larger capture of La was observed for the pristine clay, while this effect was negligible in the case of modified clay. La, Y, and Nd had the same valence but belonged to different groups; therefore, they exhibited different dimensions and, also, different electron configurations and properties, as summarized in Table 1, based on the references cited in the text. In this work, no further experimental measurements of physicochemical properties were deemed necessary.

Table 1. Metal properties [38-40].

\begin{tabular}{|c|c|c|c|c|c|c|}
\hline Ion & $\begin{array}{c}\text { Ion Ionic Radius/Å } \\
{[38]}\end{array}$ & $\begin{array}{c}\text { Ionic Radius/Å } \\
{[40]}\end{array}$ & $\begin{array}{l}\text { Hydrated } \\
\text { Radius/A }\end{array}$ & $\begin{array}{l}\text { HSAB Hardness } \\
\text { Index (Hard Soft } \\
\text { Acid-Base model) }\end{array}$ & $\begin{array}{c}\log \\
\text { K }_{\text {hydrolisis }}\end{array}$ & $\begin{array}{l}\text { Hydration } \\
\text { Enthalpy/ } \\
\mathrm{kJ} \cdot \mathrm{mol}^{-1}\end{array}$ \\
\hline $\mathrm{La}^{3+}$ & 1.06 & 1.216 & 4.52 & 0.171 & -8.5 & -3296 \\
\hline $\mathrm{Nd}^{3+}$ & 0.99 & 1.163 & 4.52 & 0.154 & -8 & -3420 \\
\hline $\mathrm{Y}^{3+}$ & 0.90 & 1.019 & 4.53 & 0.151 & -7.7 & -3583 \\
\hline $\mathrm{Ca}^{2+}$ & 0.99 & 1.12 & 4.12 & 0.181 & -12.7 & \\
\hline
\end{tabular}

Considering the complexity of the problem, the effects of the different physicochemical properties on the ion-sorbent interaction were analysed separately.

As the first step, the order of the total ion uptake of different metals showed good correlation to the ionic radius: an increased metal radius allowed for the interaction with a larger number of neighbouring adsorption sites and stabilized the adsorbed state [41]. The hydrated radius can have an effect on the diffusion of cations and accessibility to clay pores [42]; however, the interaction at the surface of the solid sorbent should be affected mainly by the ionic radius, the cation losing its hydration water in the interaction. Moreover, hydration water is less strongly held by large ions. According to this, La ions 
exhibit the highest ionic radius and the highest adsorption uptake, and there is an almost linear decreasing of the metal adsorption uptake at the decreasing ionic radius, from $\mathrm{Nd}$ to Y. Our results agree with data reported by Padilla Ortega et al. [42], who finally reported an increased selectivity in the metal adsorption onto natural clays such as bentonite or sepiolite related to the increased (not hydrated) ionic radius in binary metal systems $\mathrm{Cd} / \mathrm{Ni}$, $\mathrm{Cd} / \mathrm{Zn}$, and $\mathrm{Pb} / \mathrm{Cu}$ [42]. These data evidenced that there is no limit to accessibility of the metal cations to the matrix adsorption sites due to the ion dimensions. A very similar effect of the ionic radius was demonstrated over even more complex biomass-based solid sorbents, such as algal biomass [43], active carbons [44], and forest wastes [45].

On the other side, other, less evident properties such as the electronegativity of metals, as well as ionisation potential, were evaluated and reviewed to explain the affinity of metals with clays and other solid sorbents. In this hypothesis, high electronegativity should give an indication of the strength of the "adherence" of the metal ions to the surface, attracting the shared electrons, and should correspond to a high sorption capacity [37,46-49]. However, the application of this parameter can be questionable, and an analysis of our data showed a negative correlation between the total ion uptake observed in our conditions and values of electronegativity, i.e., La has the lowest electronegativity in a Pauling scale (1.10) but shows the highest uptake values in Region II. This observation is in agreement with the results from Padilla Ortega et al. [42].

As evidenced in Figure 2 for the total ion uptake, the $\mathrm{Y}^{3+}$ uptake increased rapidly, and, on modified clay, it equalled $\mathrm{La}^{3+}$ at the last point of the curve (Region III). Variations in the metal uptake with concentrations were also reported and discussed by Ma et al. for the selective adsorption ability of mixed solutions of $\mathrm{Pb}, \mathrm{Cu}, \mathrm{Cd}, \mathrm{Mn}$, and Fe on a double network hydrogel based on humic substances (PAA/HS gel) [47]. Their results suggested that the metal affinity was not only due to the metal properties, such as electronegativity or, in our case, the larger ion dimensions, as discussed above. Indeed, the uptake mechanism played a crucial role, as proposed in the previous paragraphs. From the comparison of Figures 2 and 3, we noticed that $\mathrm{Y}^{3+}$ removal from a solution, by ion exchange, steadily increased at increasing concentrations over both the pristine and modified clays. This effect could be related to the high charge density that will favour the exchange with Ca ions within the clay layers in both the STX and STX-L6 solids. A positive entropic contribution could also be evaluated in this process, considering that a smaller number of $\mathrm{M}^{3+}$ ions exchanged in the clay structure a greater number of $\mathrm{Ca}^{2+}$ ions consequently released in the solution. Possibly, the effect of small ion dimensions could become relevant at increasing concentrations, enhancing the ion mobility within the clay layers, although this effect should also favour $\mathrm{Nd}$ ion uptake. On the other side, excluding some discrepancies at the lowest initial concentrations, the order of the ion uptakes through the surface adsorption mechanism over STx clay is very similar to the one previously commented on for the total ion uptake, roughly following the ion dimensions scale (Figure 4). Modified clay favours the adsorption/coordination of La and $\mathrm{Nd}$ ions, prior to $\mathrm{Y}$ ions, although the uptake of $Y$ ions increases abruptly at the highest metal concentration, and in this condition, the three ions finally show very close affinity for the sorbent. The coordination of transition metals with neutral amino groups, hard Lewis bases, must indeed play a role, as previously demonstrated by FTIR spectroscopy [24].

The ion uptakes can also be related to the hydrolysis constant (stability constant of the metal hydroxide), although a clear trend cannot be detected in our systems (Table 1). This property was reported, together with the ion dimensions, as a factor influencing the favourable adsorption of $\mathrm{Pb}$ by biochars, likely through complexation or adsorption mechanisms [50,51]. On the other side, the relatively low affinity of $\mathrm{Y}$ ions for the adsorption/coordination processes in the lowest concentration range can be explained, considering that smaller metal ions possess lower hydration enthalpies and are less prone to the loss of water molecules in the hydration sphere, which should be the first step of adsorption/coordination at the sorbent surface. 
Finally, the presence of significant amounts of residual $\mathrm{Ca}$ ions in all adsorption conditions can be explained considering that, in the HSAB (Hard Soft Acid-Base model) hardness sequence, the $\mathrm{Ca}$ ion is classified as the hardest acid among the ions considered in this study, so the most difficult to be exchanged by transition metal ions [38].

\subsubsection{Release}

Release tests were performed by a treatment of the solids in strong acid conditions $(\mathrm{pH}=1)$; their analysis can be useful to get information on the ion-sorbent interaction strength. The release results as a function of the total uptake are plotted in Figure $6 \mathrm{a}, \mathrm{b}$ for STx and STx-L6, respectively.
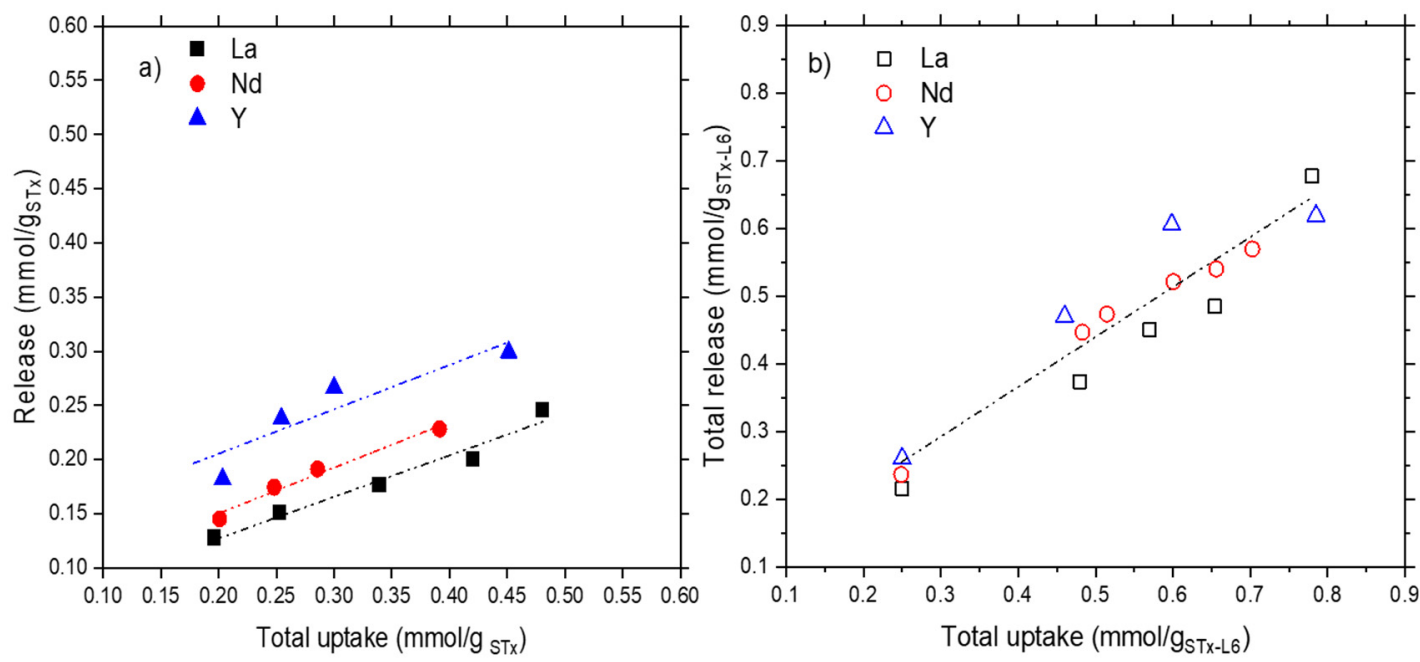

Figure 6. Release as a function of the total uptake in (a) pristine STx and (b) modified STx-L6.

A linear trend was observed for both sorbent solids. In STx, the total release was always $22-23 \%$ lower than that of STx-L6. This can be explained with the higher capture observed for STx-L6, which was always 37-38\% higher than that of STx. However, $15 \%$ of the extra ions captured by STx-L6 were still retained, despite the harsh release condition $(\mathrm{pH}=1)$.

In the case of STx, the trend lines are parallel, suggesting that the release of the three ions occur at different extents but with the same mechanism. $\mathrm{Y}$ release was easier than those of $\mathrm{Nd}$ and La (Figure 6a).

As was found in the case of the total uptake, the release of the three ions in STx-L6 were very close in both the qualitative and quantitative points of view (Figure 6b), and all the values were well-interpolated by a common trend line (Figure $6 \mathrm{~b}$ ).

The total release never corresponded to the total uptake, being about the $70 \%$ of the total capture for STx and 90\% for STx-L6, respectively. Therefore, both solids manifested a tendency to trap part of the ions in a stronger way, so that the captured ions cannot be all leached out, in spite of the acidity of the release solution $(\mathrm{pH}=1)$. The organoclay appeared more prone to a release reaction.

It has been reported that release reactions in these solids are essentially $\mathrm{pH}$-dependent; when they are treated at with $\mathrm{HNO}_{3}$ at $\mathrm{pH}=1$, protons compete with captured ions for interlayer sites and are able to replace $\mathrm{Y}, \mathrm{Nd}$, and $\mathrm{La}$ in the interlayer $[20,24]$. At the same time, nitrate groups can also interact with ions adsorbed at the surface and remove them.

The observed responses to the release conditions can be explained by referring to the uptake behaviour previously discussed and to the different mechanisms active during capture.

Indeed, in STx, the ions are captured via an exchange mechanism and via surface adsorption. Possibly, exchanged ions more strongly interact with the solids, being required to maintain electroneutrality; therefore, a total ion replacement with protons is hard to 
occur. Accordingly, it can be assumed that the residual 30\% of Y, La, and Nd not released are possibly allocated in the interlayer in view of the expected stronger interactions (i.e., charge compensation).

From a quantitative point of view, the different release extents observed for the different ions can also be explained considering the ion-solid interactions. The largest release was found for $\mathrm{Y}$ ions, which were captured in the lowest extent and mainly via exchange mechanism. Y ions, mainly occupying interlayer positions, thus possibly more strongly interact with the solid; therefore, they yet could be more involved in the exchange with protons. Protons, indeed, are able to replace interlayer cations effectively. In addition to that, $\mathrm{Y}$ ions are present in lower amounts than $\mathrm{Nd}$ or La ions, due to their lower total capture. Therefore, $\mathrm{Y}$ ions, present in a lower amount and preferentially exchanged, could be more prone to release reaction.

In the case of STx-L6, the same phenomena occurring in STx can be present, but in addition, the coordination mechanism has to be considered. Additionally, in the case of coordinated ions, the $\mathrm{pH}$ is the determining parameter. The release of coordinated ions occurs by protonation of the amino groups of polyamine, losing the coordination capability $[21,24]$. Amine protonation is probably faster and more favoured than clay protonation, which requires an exchange process; thus, $20 \%$ of the additional release in STx-L6 can be ascribed to this contribution.

\subsection{Trioninc Solutions}

Preliminary tests on multi-ion solutions were also performed to evaluate a possible "matrix" effect, which can imply different speciation in the solution, preferential adsorption, or ion competition. In Figure 7, the total (a), exchanged (b), and adsorbed or adsorbed and coordinated (c) uptakes on both STX and STx-L6 at increasing ion contents are plotted. In the initial solutions, the ratio among the ions was always kept: $\mathrm{La} / \mathrm{Nd} / \mathrm{Y}=1 / 1 / 1$ $\left(\mathrm{mmol}_{\text {ion }} / \mathrm{g}_{\text {sorbent }}\right)$.
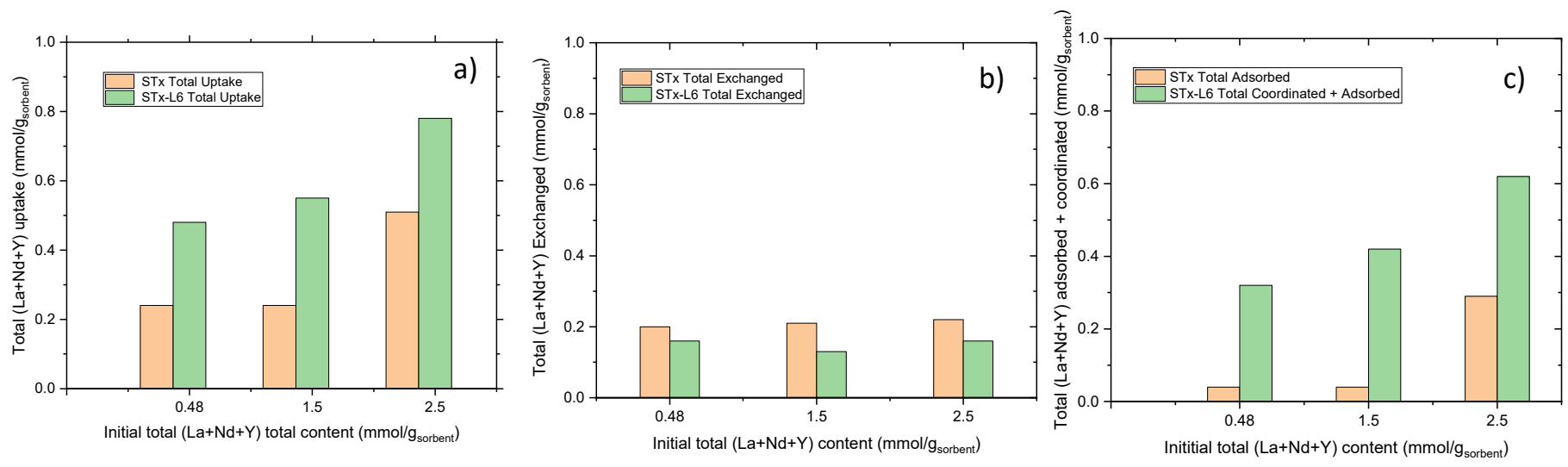

Figure 7. Uptake in trionic solution: (a) total, (b) exchanged, and (c) adsorbed/coordinated at increasing initial ion contents for pristine STx and modified STx-L6.

A behaviour similar to monoionic solutions was found. On the increasing total initial ion contents, the total uptake increases mainly when STx-L6 is used as a sorbent (Figure 7a). Additionally, in this case, the total uptake was split in the components discussed above, i.e., exchanged, adsorbed, and coordinated plus adsorbed. A constant exchange reaction was measured, which depends on the number of $\mathrm{Ca}$ ions exchangeable with the REs (Figure $\mathrm{7b}$ ). As in case of the single ion solutions, the lower exchange of STx-L6 can be attributed to the effect of the steric hindrance of polyamine in the interlayer, thus hampering by steric hinderance the interaction between the REs and the interlayer. Finally, polyamine, being able to coordinate the ions, is responsible for the additional contribution to the capture (Figure 7c). 
The analysis of the surface adsorption data in STx at the highest initial ions content (Figure $7 \mathrm{c}$ ) is remarkable. The sharp increase in the total uptake at $2.5 \mathrm{mmol}_{\text {ion }} / \mathrm{g}_{\text {sorbent }}$ ) (Figure 7a) cannot be explained on the basis of the exchange mechanism.

As a matter of fact, the exchange reaction in STx is constant (Figure 7b). On increasing the ion contents, the interlayer sites are fully saturated, and excess captured ions are allocated via the clay surface adsorption mechanism. This analysis, however, does not evidence any sorbent selectivity towards the ions. This point is of paramount importance, considering that Rare Earths separation is still an open problem.

In Figure 8, a comparison among the uptake of $\mathrm{La}, \mathrm{Nd}$, and $\mathrm{Y}$ in a single ion solution and in trionic solutions is reported for both pristine STx and modified STx-L6. The initial content $\left(0.5 \mathrm{mmol}_{\text {ion }} / \mathrm{g}_{\text {sorbent }}\right)$ of each ion was selected in both the monoionic and trionic solutions.

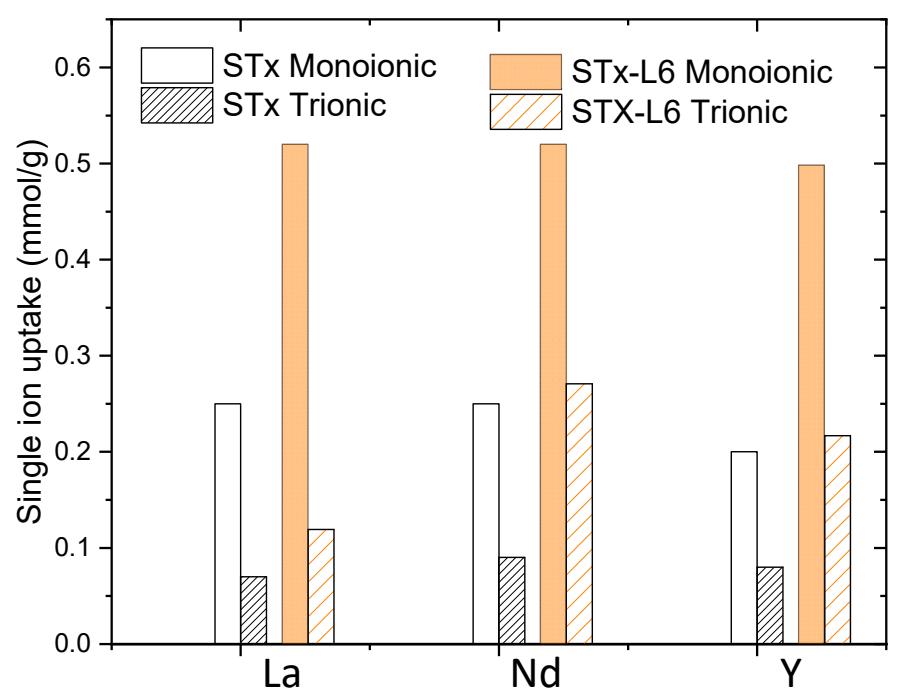

Figure 8. La, Nd, and Y uptakes by pristine STx and modified STx-L6: comparisons between the single ion and trionic solutions (solution ionic concentration $=0.5 \mathrm{mmol}_{\text {ion }} / \mathrm{g}_{\text {sorbent }}$ ).

It is evident that, despite the same initial ion contents, $\mathrm{La}, \mathrm{Nd}$, and $\mathrm{Y}$ were captured to a larger extent when a single ion solution was considered. This behaviour was preserved when both the sorbent solids were applied. Such a behaviour pointed out site competition among the ions when co-present. Moreover, the different speciation in the trionic solution can also not be discarded. Very recently, a similar mutual interference was also observed by $\mathrm{Qu}$ et al. [52] in a ternary $\mathrm{Pb}-\mathrm{Cd}-\mathrm{Ni}$ system over functionalised cellulose. However, also, some effects of the ion natures can be evidenced; indeed, $\mathrm{Nd}$ ions are always better captured in trionic solutions than La and Y. However, our experimental data did not evidence any clear trend of preferential adsorption, and this topic certainly deserves further investigation.

\section{Conclusions}

The removal of Rare Earth ions from aqueous solutions is effective on both natural STx clay and amine-modified STx. The contribution of different sorption mechanisms (surface adsorption, ion exchange, and coordination on the organic moieties) was proposed. In a single ion investigation, the total ion uptake was indeed affected by the nature of the matrix, as well as by the nature of the ions-for instance, the ion dimensions.

Regarding the release process, a linear trend was observed for both sorbent solids. The total release never corresponded to the total uptake. Therefore, both solids manifested a tendency to trap part of the ions in a stronger way, so that the captured ions could not be all leached out, in spite of the acidity of the release solution $(\mathrm{pH}=1)$. The organoclay appeared more prone to the release reaction.

A behaviour similar to the monoionic solutions was found for the trionic one. On increasing the total initial ion content, the total uptake increased when STx-L6 was used as 
sorbent. Additionally, in this case, the total uptake was split into three components: i.e., exchanged, adsorbed, and coordinate plus adsorbed.

Despite the same initial ion contents, $\mathrm{La}, \mathrm{Nd}$, and $\mathrm{Y}$ were captured in a larger extent when a single ion solution was considered. This behaviour was found for both the sorbent solids. The site competition, different speciation in the trionic solution, and ion natures could be responsible for such behaviours.

Supplementary Materials: The following are available online at https:/ / www.mdpi.com/2075-163 X/11/1/30/s1: Table S1: Initial solution composition and ion contents in the contacting solutions. Figures S1-S4 Medusa plots of the monoionic and trionic solutions.

Author Contributions: C.C.: conceptualization, methodology, supervision, and writing-review and editing; E.M.I.Z.: investigation, methodology, validation, and writing—original draft; M.B.: validation and formal analysis; G.D.: validation, formal analysis, and funding acquisition; E.F.: investigation, validation, supervision, and writing — review and editing; S.L.: data curation, and investigation; G.R.: validation and writing-review and editing; and P.G.S.: resource and data curation. All authors have read and agreed to the published version of the manuscript.

Funding: This research received no external funding.

Acknowledgments: Giuseppina Gasti and Gigliola Clerici are acknowledged for the experimental support.

Conflicts of Interest: The authors declare no conflict of interest.

\section{References}

1. Balaram, V. Rare earth elements: A review of applications, occurrence, exploration, analysis, recycling, and environmental impact. Geosci. Front. 2019, 10, 1285-1303. [CrossRef]

2. Chen, Z. Global rare earth resources and scenarios of future rare earth industry. J. Rare Earths 2011, 29, 1-6. [CrossRef]

3. European Commission. Report on Critical Raw Materials for the EU-Ad Hoc Working Group on Defining Critical Raw Materials; European Commission: Brussels, Belgium, 2014.

4. Kegl, T.; Košak, A.; Lobnik, A.; Novak, Z.; Kralj, A.K.; Ban, I. Adsorption of rare earth metals from wastewater by nanomaterials: A review. J. Hazard. Mater. 2020, 386, 121632. [CrossRef] [PubMed]

5. Kulaksiz, S.; Bau, M. Anthropogenic dissolved and colloid/nanoparticle-bound samarium, lanthanum and gadolinium in the Rhine River and the impending destruction of the natural rare earth element distribution in rivers. Earth Planet. Sci. Lett. 2013, 362, 43-50. [CrossRef]

6. Funari, V.; Bokhari, S.N.H.; Vigliotti, L.; Meisel, T.; Braga, R. The rare earth elements in municipal solid waste incinerators ash and promising tools for their prospecting. J. Hazard. Mater. 2016, 301, 471-479. [CrossRef] [PubMed]

7. Funari, V.; Braga, R.; Bokhari, S.N.H.; Dinelli, E.; Meisel, T. Solid residues from Italian municipal solid waste incinerators: A source for "'critical'" raw materials. Waste Manag. 2015, 45, 206-216. [CrossRef] [PubMed]

8. Tsamis, A.; Coyne, M. Recovery of Rare Earths from Electronic Wastes: An Opportunity for High-Tech SMEs; Directorate-General for Internal Policies of the Union (European Parliament): Brussels, Belgium, 2015.

9. Making Raw Materials Available for Europe's Future Wellbeing Proposal for a European Innovation Partnership on Raw Materials European Innovation Partnership on Raw Materials-COM(2012) 82 Final; European Commission: Brussels, Belgium, 2012.

10. Ilyas, S.; Lee, J.C.; Kim, B.S. Bioremoval of heavy metals from recycling industry electronic waste by a consortium of moderate thermophiles: Process development and optimization. J. Clean. Prod. 2014, 70, 197-202. [CrossRef]

11. Bigum, M.; Brogaard, L.; Christensen, T.H. Metal recovery from high-grade WEEE: A life cycle assessment. J. Hazard. Mater. 2012. [CrossRef]

12. Menikpura, S.N.M.; Santo, A.; Hotta, Y. Assessing the climate co-benefits from Waste Electrical and Electronic Equipment (WEEE) recycling in Japan. J. Clean. Prod. 2014, 74, 183-190. [CrossRef]

13. Binnemans, K.; Jones, P.T.; Blanpain, B.; Van Gerven, T.; Yang, Y.; Walton, A.; Buchert, M. Recycling of rare earths: A critical review. J. Clean. Prod. 2013, 51, 1-22. [CrossRef]

14. Xavier, L.H.; Giese, E.C.; Ribeiro-Duthie, A.C.; Lins, F.A.F. Sustainability and the circular economy: A theoretical approach focused on e-waste urban mining. Resour. Policy 2019, 101467. [CrossRef]

15. Sabot, J.-L.; Maestro, P. Lanthanides. In Kirk-Othmer Encyclopedia of Chemical Technology; John Wiley \& Sons, Inc.: Hoboken, NJ, USA, 2000.

16. Cui, J.; Zhang, L. Metallurgical recovery of metals from electronic waste: A review. J. Hazard. Mater. 2008, 158, 228-256. [CrossRef] [PubMed] 
17. Iannicelli-Zubiani, E.M.; Giani, M.I.; Recanati, F.; Dotelli, G.; Puricelli, S.; Cristiani, C. Environmental impacts of a hydrometallurgical process for electronic waste treatment: A life cycle assessment case study. J. Clean. Prod. 2017, 140, 1204-1216. [CrossRef]

18. Lourenço, M.A.O.; Figueira, P.; Pereira, E.; Gomes, J.R.B.; Lopes, C.B.; Ferreira, P. Simple, mono and bifunctional periodic mesoporous organosilicas for removal of priority hazardous substances from water: The case of mercury(II). Chem. Eng. J. 2017, 322, 263-274. [CrossRef]

19. Eivazihollagh, A.; Svanedal, I.; Edlund, H.; Norgren, M. On chelating surfactants: Molecular perspectives and application prospects. J. Mol. Liq. 2019, 278, 688-705. [CrossRef]

20. Iannicelli-Zubiani, E.M.; Cristiani, C.; Dotelli, G.; Stampino, P.G.; Pelosato, R.; Mesto, E.; Schingaro, E.; Lacalamita, M. Use of natural clays as sorbent materials for rare earth ions: Materials characterization and set up of the operative parameters. Waste Manag. 2015, 46, 546-556. [CrossRef]

21. Iannicelli-Zubiani, E.M.; Cristiani, C.; Dotelli, G.; Stampino, P.G. Recovery of valuable metals from electronic scraps by clays and organo-clays: Study on bi-ionic model solutions. Waste Manag. 2017, 60, 582-590. [CrossRef]

22. Du, W.; Wang, X.; Chen, G.; Zhang, J.; Slaný, M. Synthesis, property and mechanism analysis of a novel polyhydroxy organic amine shale hydration inhibitor. Minerals 2020, 10, 128. [CrossRef]

23. Slaný, M.; Jankovič, L'.; Madejová, J. Structural characterization of organo-montmorillonites prepared from a series of primary alkylamines salts: Mid-IR and near-IR study. Appl. Clay Sci. 2019, 176, 11-20. [CrossRef]

24. Cristiani, C.; Iannicelli-Zubiani, E.M.; Bellotto, M.; Dotelli, G.; Finocchio, E.; Latorrata, S.; Ramis, G.; Gallo Stampino, P. Capture and release mechanism of La ions by new polyamine-based organoclays: A model system for rare-earths recovery in urban mining process. J. Environ. Chem. Eng. 2020, 104730. [CrossRef]

25. Galamboš, M.; Suchánek, P.; Rosskopfová, O. Sorption of anthropogenic radionuclides on natural and synthetic inorganic sorbents. J. Radioanal. Nucl. Chem. 2012, 293, 613-633. [CrossRef]

26. Viglašová, E.; Daňo, M.; Galamboš, M.; Krajňák, A.; Rosskopfová, O.; Rajec, P. Investigation of Cu(II) adsorption on Slovak bentonites and illite/smectite for agricultural applications. J. Radioanal. Nucl. Chem. 2017, 314, 2425-2435. [CrossRef]

27. Krajňák, A.; Viglašová, E.; Galamboš, M.; Krivosudský, L. Kinetics, thermodynamics and isotherm parameters of uranium(Vi) adsorption on natural and hdtma-intercalated bentonite and zeolite. Desalin. Water Treat. 2018, 127, 272-281. [CrossRef]

28. Zhu, R.; Chen, Q.; Zhou, Q.; Xi, Y.; Zhu, J.; He, H. Adsorbents based on montmorillonite for contaminant removal from water: A review. Appl. Clay Sci. 2016, 123, 239-258. [CrossRef]

29. Liu, X.; Zhou, F.; Chi, R.; Feng, J.; Ding, Y.; Liu, Q. Preparation of modified montmorillonite and its application to rare earth adsorption. Minerals 2019, 9, 747. [CrossRef]

30. Alshameri, A.; He, H.; Xin, C.; Zhu, J.; Xinghu, W.; Zhu, R.; Wang, H. Understanding the role of natural clay minerals as effective adsorbents and alternative source of rare earth elements: Adsorption operative parameters. Hydrometallurgy 2019, 185, 149-161. [CrossRef]

31. Yu, B.; Hu, Z.; Zhou, F.; Feng, J.; Chi, R. Lanthanum (III) and Yttrium (III) Adsorption on Montmorillonite: The Role of Aluminum Ion in Solution and Minerals. Miner. Process. Extr. Metall. Rev. 2020, 41, 107-116. [CrossRef]

32. Cristiani, C.; Iannicelli-Zubiani, E.M.; Dotelli, G.; Finocchio, E.; Stampino, P.G.; Licchelli, M. Polyamine-based organo-clays for polluted water treatment: Effect of polyamine structure and content. Polymers 2019, 11, 897. [CrossRef]

33. Kühnel, R.A. Handbook of determinative methods in clay mineralogy. Appl. Clay Sci. 1990, 5, 190-191. [CrossRef]

34. Pokrić, B.; Branica, M.; Furedi, H.; Orhanović, Z. Precipitation and Hydrolysis of Metallic Ions. III. Studies on the Solubility of Yttrium and Some Rare Earth Hydroxides. Croat. Chem. Acta 1966, 38, 269.

35. Han, K.N. Characteristics of precipitation of rare earth elements with various precipitants. Minerals 2020, 10, 178. [CrossRef]

36. Finocchio, E.; Baccini, I.; Cristiani, C.; Dotelli, G.; Gallo Stampino, P.; Zampori, L. Hybrid organo-inorganic clay with nonionic interlayers. Mid- and near-IR spectroscopic studies. J. Phys. Chem. A 2011, 115, 7484-7493. [CrossRef] [PubMed]

37. Malamis, S.; Katsou, E. A review on zinc and nickel adsorption on natural and modified zeolite, bentonite and vermiculite: Examination of process parameters, kinetics and isotherms. J. Hazard. Mater. 2013, 252-253, 428-461. [CrossRef] [PubMed]

38. Kinraide, T.B.; Yermiyahu, U. A scale of metal ion binding strengths correlating with ionic charge, Pauling electronegativity, toxicity, and other physiological effects. J. Inorg. Biochem. 2007, 101, 1201-1213. [CrossRef]

39. Smith, D.W. Ionic hydration enthalpies. J. Chem. Educ. 1977, 54, 540-542. [CrossRef]

40. Persson, I. Hydrated metal ions in aqueous solution: How regular are their structures? Pure Appl. Chem. 2010, 82, 1901-1917. [CrossRef]

41. Ding, Y.; Liu, Y.; Liu, S.; Li, Z.; Tan, X.; Huang, X.; Zeng, G.; Zhou, Y.; Zheng, B.; Cai, X. Competitive removal of Cd(II) and Pb(II) by biochars produced from water hyacinths: Performance and mechanism. RSC Adv. 2016, 6, 5223-5232. [CrossRef]

42. Padilla-Ortega, E.; Leyva-Ramos, R.; Flores-Cano, J.V. Binary adsorption of heavy metals from aqueous solution onto natural clays. Chem. Eng. J. 2013, 225, 535-546. [CrossRef]

43. Ferreira, L.S.; Rodrigues, M.S.; de Carvalho, J.C.M.; Lodi, A.; Finocchio, E.; Perego, P.; Converti, A. Adsorption of $\mathrm{Ni}^{2+}, \mathrm{Zn}^{2+}$ and $\mathrm{Pb}^{2+}$ onto dry biomass of Arthrospira (Spirulina) platensis and Chlorella vulgaris. I. Single metal systems. Chem. Eng. J. 2011, 173, 326-333. [CrossRef] 
44. Cristiani, C.; Bellotto, M.; Dotelli, G.; Finocchio, E.; Latorrata, S.; Ramis, G.; Gallo Stampino, P.; Iannicelli-Zubiani, E.M. Rivalorizzazione di metalli da RAEE (Rivalorization of metals from WEEE). La Chim. e l'Industria Online 2020, IV, 30-34. (In Italian) [CrossRef]

45. Vázquez, G.; González-Álvarez, J.; Freire, S.; López-Lorenzo, M.; Antorrena, G. Removal of cadmium and mercury ions from aqueous solution by sorption on treated Pinus pinaster bark: Kinetics and isotherms. Bioresour. Technol. 2002, 82, 247-251. [CrossRef]

46. McKay, G.; Porter, J.F. Equilibrium Parameters for the Sorption of Copper, Cadmium and Zinc Ions onto Peat. J. Chem. Technol. Biotechnol. 1997, 69, 309-320. [CrossRef]

47. Ma, J.; Luo, J.; Liu, Y.; Wei, Y.; Cai, T.; Yu, X.; Liu, H.; Liu, C.; Crittenden, J.C. Pb(ii), Cu(ii) and Cd(ii) removal using a humic substance-based double network hydrogel in individual and multicomponent systems. J. Mater. Chem. A 2018, 6, 20110-20120. [CrossRef]

48. Zhou, G.; Luo, J.; Liu, C.; Chu, L.; Crittenden, J. Efficient heavy metal removal from industrial melting effluent using fixed-bed process based on porous hydrogel adsorbents. Water Res. 2018, 131, 246-254. [CrossRef] [PubMed]

49. Hadi, P.; Barford, J.; McKay, G. Toxic heavy metal capture using a novel electronic waste-based material-Mechanism, modeling and comparison. Environ. Sci. Technol. 2013, 47, 8248-8255. [CrossRef]

50. Ni, B.J.; Huang, Q.S.; Wang, C.; Ni, T.Y.; Sun, J.; Wei, W. Competitive adsorption of heavy metals in aqueous solution onto biochar derived from anaerobically digested sludge. Chemosphere 2019, 219, 351-357. [CrossRef]

51. Ricordel, S.; Taha, S.; Cisse, I.; Dorange, G. Heavy metals removal by adsorption onto peanut husks carbon: Characterization, kinetic study and modeling. Sep. Purif. Technol. 2001, 24, 389-401. [CrossRef]

52. Qu, J.; Tian, X.; Jiang, Z.; Cao, B.; Akindolie, M.S.; Hu, Q.; Feng, C.; Feng, Y.; Meng, X.; Zhang, Y. Multi-component adsorption of $\mathrm{Pb}(\mathrm{II}), \mathrm{Cd}(\mathrm{II})$ and $\mathrm{Ni}(\mathrm{II})$ onto microwave-functionalized cellulose: Kinetics, isotherms, thermodynamics, mechanisms and application for electroplating wastewater purification. J. Hazard. Mater. 2020, 387, 121718. [CrossRef] 